\section{Fusion of Zif268 to the C-Terminus of Scfvs Promotes Expression of the Active Form in the Cytoplasm of Escherichia coli}

\section{Abstract}

The expression of functional scFvs in Escherichia coli cytoplasm at high yields remains a challenge, because the reducing environment of the cytoplasm inhibits disulfide bond formation, which is essential for efficient and appropriate folding of scFvs. Thus, to address this challenge, we aimed to develop a method for the efficient functional expression of scFvs in E. coli cytoplasm. The scFv against rabbit $\operatorname{lgG}(\mathrm{scFv}(\mathrm{A} 10 \mathrm{~B}))$ fused with Zif268 at its C-terminus was expressed at high levels in the cytoplasm of $E$. coli in a soluble and active form. The reactivity Zif268-fused scFv against the antigen was identical to that of un-fused scFv(A10B). In contrast, un-fused $\mathrm{scFv}(\mathrm{A} 10 \mathrm{~B})$ can be produced in a functional form only when expressed in the oxidizing environment of the periplasmic space, which limits expression quantities. Fusion with maltose-binding protein (MBP) did not improve expression. We compared the productivity and functionality of un-fused and Zif268-fused proteins by using several scFvs derived from hybridomas and a chicken scFv phage display library. We found that Zif268-fused scFvs are expressed at a high level in the cytoplasm of $E$. coli as soluble and active proteins.

Keywords: Single-chain variable fragment; Expression; Escherichia coli Zif268; Cytoplasm; Fusion protein

Abbreviations: E. coli: Escherichia coli; PBS: Phosphate-Buffered Saline; scFv: Single-Chain Variable Fragment; Fab: Fragment Antigen-Binding; PBS-T: PBS With 0.05\% Tween 20; Trpr: Tryptophan Transcriptional Repressor

Received: March 23, 2016; Accepted: April 22, 2016; Published: April 27, 2016
Mieko Kato ${ }^{1}$ and Yoshiro Hanyu ${ }^{2}$

1 Bio-Peak Co. Ltd., Shimonojo, Takasaki, Japan

2 Structure Physiology Research Group, Biomedical Research Institute, National Institute of Advanced Industrial Science and Technology (AIST), Higashi, Tsukuba, Japan

Corresponding author:

Dr. Yoshiro Hanyu

戸y.hanyu@aist.go.jp

Structure Physiology Research Group, Biomedical Research Institute, National Institutes of Advanced Industrial Science and Technology (AIST), 1-1-1 Higashi, Tsukuba, 305-8566 Japan.

\section{Tel: 81298615542}

Fax: 81298612706

Citation: Kato M, Hanyu Y. Fusion of Zif268 to the C-Terminus of Scfvs Promotes Expression of the Active Form in the Cytoplasm of Escherichia coli. Biochem Mol Biol J. 2016, 2:1.

\section{Introduction}

Recombinant antibodies are indispensable for research, diagnostics, and therapeutics [1-3]. Recombinant antibody fragments, e.g., single-chain variable fragments (scFv) and fragment antigen-binding (Fab), have advantages for research and testing [4], because they can be tailored using protein engineering approaches to add desired functions [5]. The small size and monomeric nature of scFvs have led to their broad application, including penetration of tumors [6] and genetic and chemical modification [7].

Antibody fragments, mainly scFvs, can be expressed in microbial systems that are more suitable for large-scale expression than mammalian cells [8,9]. The gram-negative bacterium Escherichia coli is the most widely used system for production of recombinant proteins, with cytoplasmic expression yields sometimes reaching more than $10 \mathrm{~g} / \mathrm{L}$. The expression of recombinant antibody fragments in the reducing cytoplasmic compartment mostly results in non-functional aggregates. Functional antibody fragments can sometimes be recovered from cytoplasmic inclusion bodies by refolding $[10,11]$, but this method is not applicable to a variety of antibody fragments. Many functional antibody fragments are expressed in the oxidizing environment of the periplasmic space of $E$. coli, which allows correct formation of disulfide bonds [12].

Periplasmic secretion can be achieved by fusing the signal sequence for $E$. coli proteins onto the $\mathrm{N}$-terminus of the antibody sequence, e.g., pectate lyase $B(p e / B)$ and outer membrane protein A $(O m p A)[13,14]$. However, the small volume of the periplasmic space limits the yield of antibody fragments. To achieve higher expression yields, further improvements are needed. Co-expression of chaperones in E. coli and mutations 
that alter the reducing cytoplasmic environment have improved the cytoplasmic expression of antibody fragments [15]. ScFvs can be expressed with a hydrophilic tag, such as maltosebinding protein (MBP), increasing their solubility in $E$. coli and improving expression yield [16-18]. Fusion of other hydrophilic tags to scFv and their improvement of expression have been studied extensively [19]. Some tags have been shown to increase expression, while decreasing the binding activity of the fused protein [20].

Currently, no universal high-yield E. coli expression system for scFvs is available [9]. Development of an effective scFv expression system will enable more effective screening of scFvs from libraries, facilitating identification of scFvs with superior affinity and specificity [21]. Establishment of a good expression system for scFvs will improve the yield, purity, and quality of scFvs.

Here, we produced a scFV-Zif268 fusion protein by fusing the DNA-binding protein Zif268 [22] to the C-terminus of ScFv and found that scFv can efficiently be expressed in this form in the cytoplasm of E. coli. We discuss the possible mechanism of scFv expression and the implications for potential biotechnological applications.

\section{Methods}

\section{Preparation of expression vectors}

Figure 1 shows a schematic representation of the expression cassette for each vector. All vectors were driven by a T7 promoter. An scFv that recognizes the constant region of rabbit IgG was constructed from the sequence of a monoclonal IgG1 antibody generated from an $\mathrm{A} 10 \mathrm{~B}$ hybridoma cell line [23]. scFv(A10B) is suitable for development of methodologies because its expression level is adequate and $\operatorname{scFv}(A 10 B)$ is stable. $\operatorname{scFv}(A 10 B)$ consists of $\mathrm{VH}$ and $\mathrm{VL}$ sequences joined by the linker sequence GGGGSGGGGSGGGGS. DNA for scFv(A10B) was synthesized by GenScript (Piscataway, NJ), digested with the EcoRI and Notl restriction enzymes, and inserted into the pET22b(+) (Merck Millipore, Darmstadt, Germany) vector for periplasmic protein expression.

The oligonucleotides for Zif268 were synthesized by GenScript and cloned into the $\mathrm{C}$-terminus of the $\mathrm{scFv}(\mathrm{A} 10 \mathrm{~B})$ vector using HindIII (New England BioLabs, Ipswich, MA) and Xhol (New England BioLabs) to create a $\operatorname{scFv}(\mathrm{A} 10 \mathrm{~B})$-Zif268 vector, or the $\mathrm{N}$-terminus of the scFv vector using $\mathrm{Ncol}$ and $\mathrm{EcoRI}$ to create a Zif268-scFv(A10B) vector. The oligonucleotides for the tryptophan transcriptional repressor (TrpR) [24] were synthesized (GenScript) and cloned into the scFv-A10B vector using HindIII and Xhol to create $\operatorname{scFv}(\mathrm{A} 10 \mathrm{~B})$-TrpR. The malE gene of pMAL-c5X (New England BioLabs) was amplified using primers with the following sequences: sense: 5'-AGGCAAGCTTAAAATCGAAGAAGGTAAACT-3' and anti-sense: 5'ACGCGCTCGAGAGTCTGCGCGTCTTTCAGG-3'.

The PCR products were digested with HindIII and Xhol, agarose gel purified, dephosphorylated, and cloned into the digested pET22b-scFv(A10B) to create pET-22b-scFv(A10B)-MBP. scFv against Gaussia luciferase [25] and ScFv against rabbit IgG from the chicken IgY library [26] have been described previously. These scFvs were digested with EcoRI and Notl and cloned into appropriate vectors to create scFv(rabbit IgG), scFv(rabbit IgG)Zif268, scFv(Gaussia luciferase) and scFv(Gaussia luciferase)Zif268.

\section{Expression of scFvs}

After the nucleotide sequences were confirmed, the resulting expression plasmids were transformed in E. coli BL21 (DE3) (Merck Millipore). The transformants were cultured at $37^{\circ} \mathrm{C}$ in $250 \mathrm{~mL}$ Lysogeny Broth (LB) medium containing $50 \mu \mathrm{g} / \mathrm{mL}$ of ampicillin until an $\mathrm{OD}_{600}$ of 0.6 was reached. The cells were then incubated at $25^{\circ} \mathrm{C}$ for an additional $6 \mathrm{~h}$ in the presence of $50 \mu \mathrm{M}$ isopropyl- $\beta-D(-)$-thiogalactopyranoside (IPTG, Takara Bio, Tokyo, Japan) and pelleted by centrifugation. Harvested cells (2.0 g) that expressed the scFvs were suspended in $25 \mathrm{ml}$ of buffer (500 $\mathrm{mM} \mathrm{NaCl}, 20 \mathrm{mM}$ Tris- $\mathrm{HCl}, \mathrm{pH}$ 7.7) containing protease inhibitors (Roche Diagnostics, Mannheim, Germany)), and disrupted by sonication. The cell lysates were centrifuged at $20000 \times \mathrm{g}$ for 30 min. The supernatants were collected as the cytoplasmic extract. The same amount of pelleted cells was suspended in $25 \mathrm{ml}$ of resuspension buffer ( $30 \mathrm{mM}$ Tris- $\mathrm{HCl}, 20 \%$ sucrose $\mathrm{pH} 8.0$ ). EDTA was added at a final concentration of $1.0 \mathrm{mM}$, and the suspension was rotated at $4^{\circ} \mathrm{C}$ for $30 \mathrm{~min}$. The cells were centrifuged at 1600 $\times \mathrm{g}$ at $4^{\circ} \mathrm{C}$ for $10 \mathrm{~min}$. The supernatants were collected as the periplasmic extract.

\section{Purification of recombinant scFvs from the periplasmic and cytoplasmic extracts}

The periplasmic supernatants for $\operatorname{scFv}(\mathrm{A} 10 \mathrm{~B})$ and the cytoplasmic supernatants for $\operatorname{scFv}(\mathrm{A} 10 \mathrm{~B})$-Zif268 were collected and diluted with binding buffer $(20 \mathrm{mM}$ phosphate, $0.5 \mathrm{M} \mathrm{NaCl}$, and $20 \mathrm{mM}$ imidazole [pH 7.6]). The diluents were filtered through a $0.22-\mu \mathrm{m}$ filter and loaded onto a 1-mL HisTrap-FF column (GE Healthcare, Wauwatosa, WI) that was equilibrated with binding buffer. The His-tagged fragments were eluted with a linear gradient of 20$500 \mathrm{mM}$ imidazole in binding buffer. The purified scFvs were dialyzed against phosphate buffered saline (PBS) $(\mathrm{pH} 7.4)$ and stored at $-30^{\circ} \mathrm{C}$.

\section{ELISA}

A 96-well ELISA plate was coated with $50 \mu \mathrm{l}$ of $5 \mu \mathrm{g} / \mathrm{ml}$ rabbit IgG per well. A blocking solution (blocking reagent for ELISA; Roche) was applied and the plate was incubated for $1 \mathrm{~h}$. After tapping out the antigen solution, $50 \mu \mathrm{l}$ of solutions containing the scFvs was added into each well and reacted for $2 \mathrm{~h}$. It was then washed with PBS-T (PBS with $0.05 \%$ Tween 20), and $50 \mu \mathrm{l}$ of PBS-T containing the anti-His antibody conjugated to horseradish peroxidase (Roche Diagnostics) was added to each well. The amount of ScFv-HRP was measured using the TMB peroxidase substrate kit (Thermo Fisher Scientific, Waltham, MA,) and the plates were read using a microplate reader (Model 680; BioRad Laboratories, Hercules, CA) at a wavelength of $450 \mathrm{~nm}$. All experiments were conducted three times, and the average signal intensity was used for analysis.

\section{Western blotting}

The scFvs were dissolved in sample buffer ( $2 \%$ sodium dodecyl sulfate [SDS], 5\% 2-mercaptoethanol, 10\% glycerol, $0.01 \%$ 
bromophenol blue, $62.5 \mathrm{mM}$ Tris- $\mathrm{HCl}\left[\mathrm{pH} \mathrm{6.8])} \mathrm{and} \mathrm{boiled} \mathrm{at} 95^{\circ} \mathrm{C}\right.$ for $5 \mathrm{~min}$. The samples were separated by SDS-polyacrylamide gel electrophoresis (SDS-PAGE) in a denaturing running buffer (containing $0.1 \%$ SDS). The gel was transferred by electrophoresis to polyvinylidene difluoride (PVDF; Bio-Rad Laboratories) membranes using a transfer buffer (without SDS). The blots were blocked in PBS-T containing 5\% nonfat dry milk. After they were washed with PBS-T, the blots were incubated with antiHis antibody conjugated to horseradish peroxidase for $2 \mathrm{~h}$ and washed with PBS-T. Subsequently, they were developed using a chemiluminescent HRP substrate kit (Immobilon Western; Merck Millipore), and the chemiluminescence signal was detected using Chemi-Stage CC16mini (KURABO, Osaka, Japan). Each band obtained by western blotting was analyzed using the Software Labo-1D (KURABO).

\section{Results}

\section{Effect of Zif268 fusion on scFv expression}

Total and active yields of scFvs were assessed by western blot and ELISA, respectively. Each band obtained by western blotting (Figure 2A) was digitized and measured (Table 1), and the expression levels were compared quantitatively. The total expression level of $\operatorname{scFv}(A 10 B)$-Zif268 was 2.8 times larger than that of $\operatorname{scFv}(A 10 B)$. While $\operatorname{scFv}(A 10 B)$ was present in both the periplasmic and cytoplasmic fractions, scFv(A10B)-Zif268 was only present in the cytoplasmic fraction. The ratio of cytoplasmic expression to total expression of scFv(A10B) and scFv(A10B)-Zif268 was $40.3 \%$ and $64.9 \%$, respectively. Thus, the fusion of Zif268 increased the cytoplasmic expression levels. Zif268-scFv(A10B) that Zif268 was fused to the $\mathrm{N}$-terminus of $\operatorname{scFv}(A 10 B)$ was not expressed (data not shown). Promotion of scFv expression by fusion of Zif268 was only observed when Zif268 was fused to the C-terminus of scFv.

Each fraction was collected and their reactivities against the antigen were measured by ELISA (Figure 2B). ScFv(A10B) from the periplasmic fraction reacted with the antigen in a dosedependent-manner, however its reactivity was weak. scFv(A10B) from the cytoplasmic fraction did not react with the antigen, while the expression level of cytoplasmic $\mathrm{scFv}(\mathrm{A} 10 \mathrm{~B})$ was 2.8 times larger than that of periplasmic $\operatorname{scFv}(A 10 B)$ (Table 1), indicating that $\mathrm{scFv}(\mathrm{A} 10 \mathrm{~B})$ in the cytoplasmic fraction loses its reactivity completely. ScFv(A10B)-Zif268 from the cytoplasmic fraction specifically recognized the antigen with the high reactivity, even after a 1000 -fold dilution. The fusion of Zif268 increased the cytoplasmic expression to 4.6 times more than that of scFv(A10B) (Table 1). Furthermore, this fusion made scFv from this fraction soluble and active. Given that the cytoplasmic expression level of scFv(A10B)-Zif268 was 13.0 times greater than the periplasmic expression level of $\mathrm{scFv}(\mathrm{A} 10 \mathrm{~B})$, we determined the change in the yield of soluble and active scFv to be increased 13-times by fusion with Zif268.

\section{Effect of the other fusion partners on scFv expression}

We compared the expression levels and ELISA signals (as mentioned above) from periplasmic and cytoplasmic fractions of the C-terminal modification to the standard ScFv formats, including MBP and TrpR (Figure 2A). The total expression level of $\mathrm{scFv}(\mathrm{A} 10 \mathrm{~B})-\mathrm{MBP}$ and $\mathrm{scFv}(\mathrm{A} 10 \mathrm{~B})-\operatorname{TrpR}$ was 1.7 and 3.3 times, respectively, greater than that of $\operatorname{scFv}(A 10 B)$. Expression patterns in the cytoplasm, periplasm, and pellet (insoluble fraction) of scFv(A10B)-MBP and scFv(A10B) TrpR were very similar to that of unfused-scFv (Table 1). Although fusion of MBP did not alter the reactivities of $s c F v$, the fusion of TrpR improved the reactivities, similar to that observed with Zif268 (Figure 2B). ScFv(A10B)$\operatorname{TrpR}$ in the cytosolic fraction showed the high reactivities like scFv(A10B)-Zif268. However, scFv(A10B)-TrpR was expressed not only in the cytoplasm but also in the periplasm; thus, it showed localization characteristics different from those of the Zif268 fusion protein (Figure 2A). ScFv(A10B)- TrpR from both of the cytoplasmic and periplasmic fractions recognized the antigen. The fusion of TrpR induced the expression of active scFvs in the cytoplasm, like the fusion of Zif268, and promoted periplasmic expression as well. The reactivity of $\operatorname{scFv}(\mathrm{A} 10 \mathrm{~B})-\mathrm{MBP}$ from the cytoplasmic fraction was as low as that of $\mathrm{scFv}(\mathrm{A} 10 \mathrm{~B})$ from the same fraction, indicating that similar to $\operatorname{scFv}(A 10 B), \operatorname{scFv}(A 10 B)-$ $\mathrm{MBP}$ in the cytoplasmic fraction loses its reactivity.

\section{Antigen binding characteristics of $\operatorname{scFv}(\mathrm{A} 10 \mathrm{~B})$ - Zif268}

ScFv(A10B) and scFv(A10B)-Zif268 were purified by metal-affinity chromatography and their reactivity was compared (Figure 3 ). Fusion of Zif268 to the C-terminus of scFv increased the scFv yield, but did not change the binding activity of scFv. The mid points of the reactions were identical and the slope of the curve was unchanged. These results show that fusion of Zif268 to the C-terminus of ScFv did not change the reactivity against the antigen.

\section{Expression conditions and the effect of Zif268 fusion}

To study how fusion of Zif268 to the C-terminus of scFv altered scFv expression, we changed the expression conditions of scFvs (Figure 4). Expression was induced at two different temperatures, $25^{\circ} \mathrm{C}$ and $30^{\circ} \mathrm{C}$. At both temperatures, the expression of $\mathrm{scFv}(\mathrm{A} 10 \mathrm{~B})$-Zif268 was higher than that of $\mathrm{scFv}(\mathrm{A} 10 \mathrm{~B})$. Expression was also induced at two different concentrations of IPTG, $50 \mu \mathrm{M}$ and $200 \mu \mathrm{M}$. At both concentrations, the expression of $\operatorname{scFv}(\mathrm{A} 10 \mathrm{~B})$-Zif268 was higher than that of $s c F v(A 10 B)$. Thus, the increased expression of $\operatorname{scFv}(A 10 B)-Z i f 268$ is not dependent on the expression conditions.

Table 1 Expression of scFvs in each fraction.

\begin{tabular}{|c|c|c|c|c|c|}
\hline & Intensity periplasm & Cytoplasm & Pellet & Total & Ratio Total Expression \\
\hline $\operatorname{scFv}(A 10 B)$ & $357 \pm 17$ (14.1\%) & $1017 \pm 49(40.3 \%)$ & $1151 \pm 59(45.6 \%)$ & $2525 \pm 125(100 \%)$ & $10 \pm 0.1$ \\
\hline $\operatorname{scFv}(A 10 B)-z i f 268$ & $0 \pm 0(0 \%)$ & $4656 \pm 215$ (64.9\%) & $2515 \pm 151(35.1 \%)$ & $7171 \pm 367(100 \%)$ & $2.8 \pm 0.2$ \\
\hline scFv(A10B)-TrpR & $1539 \pm 103(18.5 \%)$ & $3264 \pm 158(39.5 \%)$ & $3516 \pm 231(42.3 \%)$ & $8319 \pm 492(100 \%)$ & $3.3 \pm 0.2$ \\
\hline $\mathrm{scFv}(\mathrm{A} 10 \mathrm{~B})-\mathrm{MBP}$ & $895 \pm 43(21.4 \%)$ & $1704 \pm 83(40.7 \%)$ & $1588 \pm 126(27.9 \%)$ & $4187 \pm 251(100 \%)$ & $1.7 \pm 0.1$ \\
\hline
\end{tabular}




pET22b/ scFv(A10B)
pET22b/ scFv(A10B)-Zif268
pET-22b/ Zif268-scFv(A10B)
pET-22b/ scFv(A10B)-TrpR
pET-22b/ scFv(A10B)-MBP
pET22b / scFv(rabblt IgG)
pET22b / scFv(rabbit IgG)-Zif268

Figure 1 Construction of ScFv expression vectors. ScFv which recognizes rabbit IgG was cloned into the $\mathrm{pET} 22 \mathrm{~b}(+)$ vector for periplasmic protein expression, scFv(A10B). Fusion partners were inserted at the $C$-terminus of scFvs, scFv(A10)Zif268, scFv(a10B)-MBP and scFv(A10B)-TrpR. Zif268 was also inserted at the $\mathrm{N}$ terminus of scFvs, Zif268-scFv(A10). ScFv from chicken anti-rabbit IgG was cloned into the pET22b(+) vector, scFv(rabbit IgG). ScFv from mouse anti-Gaussia luciferase was cloned into the pET22b(+) vector, scFv(Gaussia luciferase).

\section{Zif268 fusion to other scFvs}

We studied whether the improvement of scFv expression by C-terminal fusion of Zif268 was restricted to $\mathrm{scFv}(\mathrm{A} 10 \mathrm{~B})$. We studied changes in the reactivity of other scFvs due to C-terminal fusion of Zif268. Anti-Gaussia luciferase from murine hybridoma [25] and anti-rabbit scFv from chicken spleen, established by phage display [26], were studied (Figure 5). The reactivity of each lysate was compared with that from scFv without C-terminal Zif268 fusion. In both scFvs, the reactivity was remarkably improved by Zif268 fusion. Thus, Zif268 fusion improved expression, not only for $\operatorname{scFv}(A 10 B)$, but also for other scFvs.

\section{Discussion}

Functional antibody fragments can be expressed in the periplasm of $E$. coli; however, the yield of these fragments is limited. Additionally, no universal high-yield $E$. coli expression system for scFvs is available [9]. Hence, in this study we aimed to develop an expression system by which scFv can be efficiently expressed as a fusion protein in the cytoplasm of $E$. coli since fusion of highly hydrophilic proteins or tags to target proteins can improve its solubility $[27,28]$. Thus, we fused Zif268 to the C-terminus of SCFv and studied its expression in $E$. coli. This fusion protein was strongly expressed in a functional and soluble form in the cytoplasm of $E$. coli. We expressed a variety of scFvs derived from hybridomas $[23,25]$ and phage display libraries [26] as Zif268 fusion proteins. All of the scFv-Zif268 proteins were expressed at higher levels than the corresponding un-fused scFvs.

Zif268, a member of the classical zinc-finger family, contains three sequential Cys2His2 zinc-binding domains that together

A

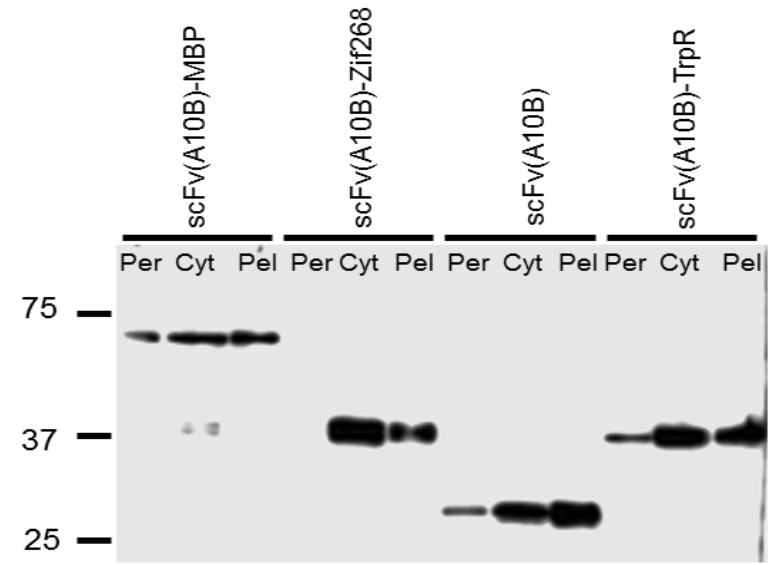

$\mathrm{kDa}$

B

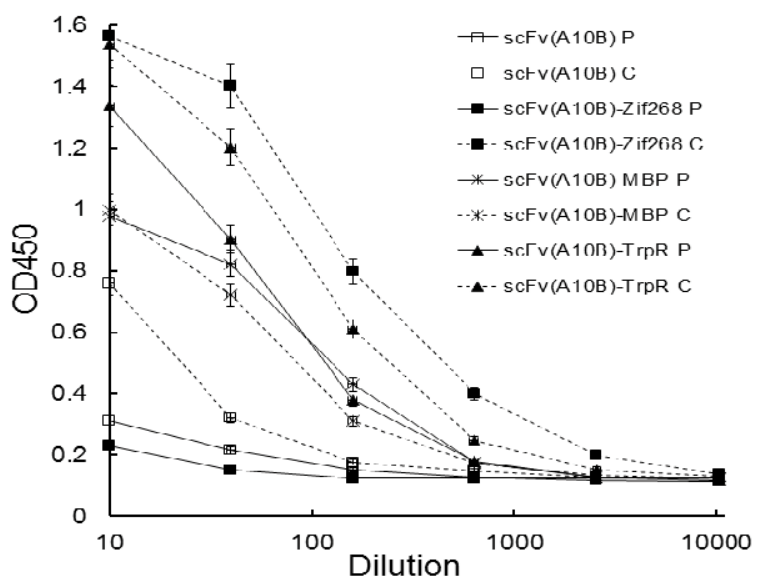

Figure 2 Cytosolic and periplasmic expression of scFvZif268. A: Western blot analysis. ScFv was paired with alternate fusion partners, Zif268, MBP, and $\operatorname{TrpR}$, and expression was measured with western blot analysis. Immunodetection of scFvs was performed using anti-His antibody conjugated with HRP. Per denotes the periplasmic fraction. Cyt denotes the cytoplasmic fraction. Pel denotes the pellet (insoluble) fraction. B: Binding activities of scFvs with different fusion partners as determined by ELISA. The reactivity of $\operatorname{scFv}(\mathrm{A} 10 \mathrm{~B})$ with the different fusion partners was measured by ELISA. The data represent the mean of 3 replicates. The error bars represent the standard deviation. 


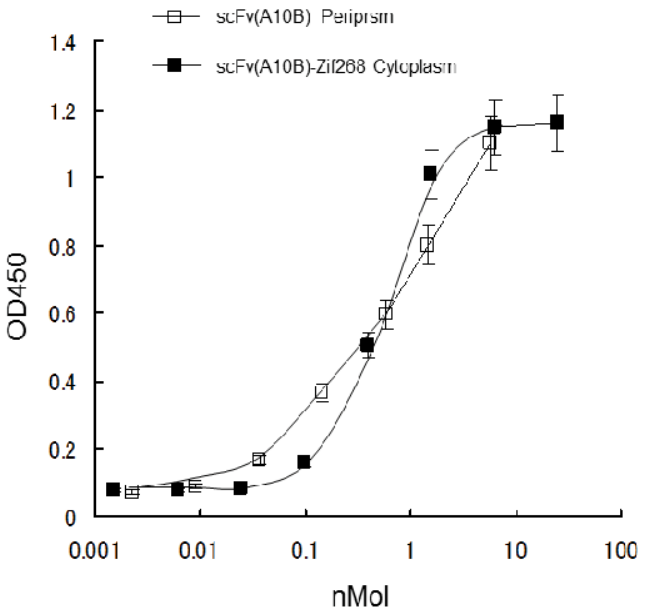

Figure 3 Binding characteristic of $\mathrm{scFv}(\mathrm{A} 10 \mathrm{~B})$ and scFv(A10B)-Zif268. The periplasmic fractions of scFv and scFv-Zif268 were further purified by metal affinity chromatography. Staining with Coomassie brilliant blue product a single band in SDS-PAGE. The reactivities of the products were determined by ELISA. The data represent the mean of 3 replicates. The error bars represent the standard deviation.

bind to a target DNA sequence of 5'-AGCGTGGGCGT-3' [29]. Each finger contains a short, two-stranded antiparallel $\beta$-sheet and an $\alpha$-helix. These domains can be fused to an endonuclease to produce a chimeric protein that cleaves specific DNA sequences, known as a zinc finger nuclease [30]. Zif268-fusion nucleases can perform precise DNA cleavage via recognition by Zif268. This site-specific nuclease is a very useful tool for gene manipulation. Enhancement of expression with Zif268 has not been reported to date. However, nucleases with Zif268 fusion are readily expressed in $E$. coli and their function is fully retained. Zif268 might stabilize the protein to which it is fused [31]. scFvs fused with Zif268 are localized in the cytoplasm, even if they possess periplasmic signal peptides at their $\mathrm{N}$-terminus. We were not able to clarify the mechanism underlying this localization, and further study is required. The mechanism underlying the observed cytoplasmic expression of scFv-Zif268 containing the pelB leader sequence is not clear. The binding of scFv-Zif268 to $E$. coli DNA might prevent migration of scFvs to the periplasmic space. To confirm this effect, further study is needed. The scFv-Zif268 expressed in the cytoplasm was functional, and it showed identical reactivity against the antigen to scFv expressed in the periplasm. It would be expected to show correct disulfide bonding; however, this would need to be verified in a future study. The mechanism of disulfide bond formation for scFv-Zif268 should also be studied.

We also investigated the effect of TrpR, another type of DNAbinding protein, which are 108 amino acids in length. TrpR recognizes specific DNA sites and binds as a dimer [32]. The fusion of TrpR to scFvs also improved the expression of scFvs, but the localization pattern differed from that of Zif268. Functional scFv-TrpR was expressed both in the cytoplasm and periplasm,

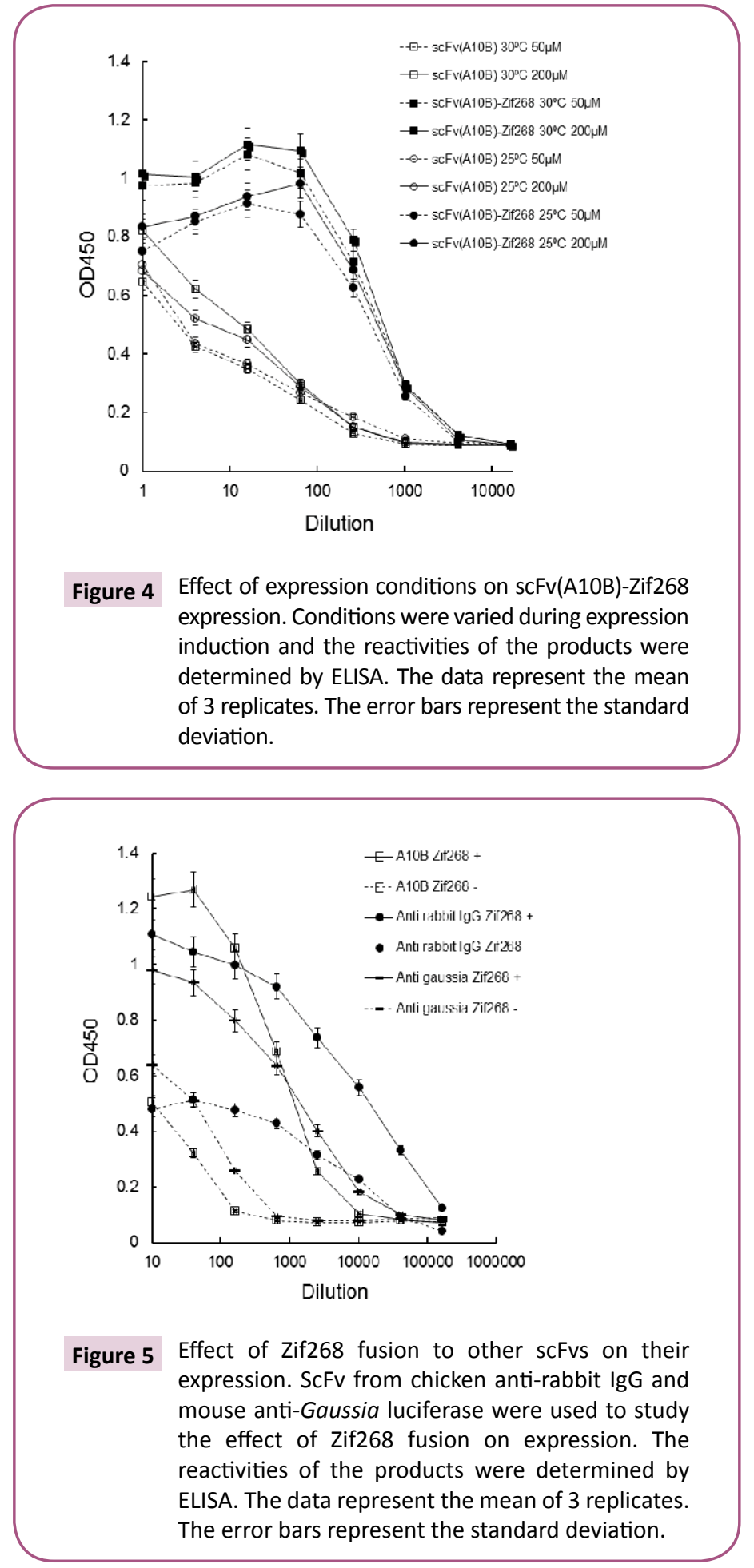

and scFv-TrpR from both fractions was functional. Both DNAbinding proteins are hydrophilic and positively charged, with an affinity to negatively charged DNA. Zif268 and TrpR, which are both globular DNA-binding proteins, are almost identical in size, at approximately $10 \mathrm{kDa}$, with 100 amino acids. These small DNA-binding motifs might bind to DNA sequences present in $E$. coli that are similar to the original recognition sequences, and thereby stabilize the structure of scFvs. The DNA binding region of Hin recombinase [33], which has the similar character, showed improved scFv expression (data not shown). 
One limitation of this study is that we only tested the effect of a limited number of scFvs. The effect of Zif268 should be evaluated using a variety of scFvs. Moreover, mutations in Zif268 might improve its effect [34]; thus, its sequence should be optimized in future experiments. Additionally, an optimal linker between scFvs and Zif268 should be determined [35] and other DNAbinding motifs should be studied. It is also important to further study the mechanism underlying cytosolic localization. This expression enhancement would be a very useful technique for scFv expression because the high yield would enable a significant reduction in the expression volume required. Reducing the assay volume will in turn increase the number of clones that can be screened from the libraries [36]. In particular, this would be useful for screening large scFv libraries.

\section{Conclusions}

ScFv was expressed as a fusion protein with Zif268 at its C-terminus. These scFvs fusion proteins were expressed at high levels in the cytoplasm of $E$. coli in a soluble and active form. The reactivity of Zif268-fused scFvs against the antigen was identical to that of unfused scFvs. Thus, C-terminal fusion of Zif268 appears to function as a tag that promotes the solubility and expression of scFvs, which will, in turn, improve their purity, yield, and stability, and increase the efficiency of screening technologies for scFvs. We hypothesize that this effect is applicable to other scFvs. However, it will be necessary to verify the effect of Zif268 using a variety of scFvs to show that this fusion is widely applicable for expression in E. coli. 


\section{References}

1 Weiner GJ (2015) Building better monoclonal antibody-based therapeutics. Nat Rev Cancer 15: 361-370.

2 Reichert JM (2015) Antibodies to watch in 2015. MAbs 7: 1-8.

3 Colwill K, Gräslund S (2011) A roadmap to generate renewable protein binders to the human proteome. Nat Methods 8: 551-558.

4 Holliger P, Hudson PJ (2005) Engineered antibody fragments and the rise of single domains. Nat Biotechnol 23: 1126-1136.

5 Schaefer JV, Lindner P, Plückthun A (2010) Miniantibodies. In: Kontermann R, Dübel S. (eds.) Springer Berlin Heidelberg, Germany.

6 Accardi L, Di Bonito P (2010) Antibodies in single-chain format against tumour-associated antigens: present and future applications. Curr Med Chem 17: 1730-1755.

7 Hagemeyer CE, von Zur Muhlen C, von Elverfeldt D, Peter K (2009) Single-chain antibodies as diagnostic tools and therapeutic agents. Thromb Haemost 101: 1012-1019.

8 Schirrmann T, Al-Halabi L, Dübel S, Hust M (2008) Production systems for recombinant antibodies. Front Biosci13: 4576-4594.

9 Frenzel A, Hust M, Schirrmann T (2013) Expression of recombinant antibodies. Front Immunol 4: 217.

10 Kudou M, Ejima D, Sato H, Yumioka R, Arakawa T, et al. Refolding single-chain antibody (scFv) using lauroyl-L-glutamate as a solubilization detergent and arginine as a refolding additive. Protein Expr Purif 2011;77:68-74. doi:10.1016/j.pep.2010.12.007.

11 Umetsu M, Tsumoto K, Hara M, Ashish K, Goda S, Adschiri T, et al. (2003) How additives influence the refolding of immunoglobulinfolded proteins in a stepwise dialysis system. Spectroscopic evidence for highly efficient refolding of a single-chain Fv fragment. J Biol Chem 278: 8979-8987.

12 Popplewell AG, Sehdev M, Spitali M, Weir ANC (2005) Expression of antibody fragments by periplasmic secretion in Escherichia coli. Methods Mol Biol 308: 17-30.

13 Van Bloois E (2012) Biotechnological applications of periplasmic expression in E. coli. Enzym Eng 01.

14 De Marco A (2009) Strategies for successful recombinant expression of disulfide bond-dependent proteins in Escherichia coli. Microb Cell Fact 8: 26.

15 Schaefer JV, Plückthun A (2010) Improving expression of scFv fragments by co-expression of periplasmic chaperones. In: Kontermann R, Dübel S, (eds.) Antib Eng, Berlin, Heidelberg: Springer Berlin Heidelberg 345-361.

16 Jurado P, Ritz D, Beckwith J, de Lorenzo V, Fernández LA (2002) Production of functional single-chain Fv antibodies in the cytoplasm of Escherichia coli. J Mol Biol 320: 1-10.

17 Bach H, Mazor Y, Shaky S, Shoham-Lev A, Berdichevsky Y, et al. (2001) Escherichia coli maltose-binding protein as a molecular chaperone for recombinant intracellular cytoplasmic single-chain antibodies. J Mol Biol 312: 79-93.

18 Hayhurst A (2000) Improved expression characteristics of singlechain Fv fragments when fused downstream of the Escherichia coli maltose-binding protein or upstream of a single immunoglobulinconstant domain. Protein Expr Purif 18: 1-10.

19 Sun W, Xie J, Lin H, Mi S, Li Z, et al. (2012) A combined strategy improves the solubility of aggregation-prone single-chain variable fragment antibodies. Protein Expr Purif 83: 21-29.

20 Martin CD, Rojas G, Mitchell JN, Vincent KJ, Wu J, et al. (2006) A simple vector system to improve performance and utilisation of recombinant antibodies. BMC Biotechnol 6: 46.

21 Hust M, Steinwand M, Al-Halabi L, Helmsing S, Schirrmann T, et al. (2009) Improved microtitre plate production of single chain Fv fragments in Escherichia coli. N Biotechnol 25: 424-428.

$22 \mathrm{Wu} \mathrm{H}$, Yang WP, Barbas CF (1995) Building zinc fingers by selection: toward a therapeutic application. Proc Natl Acad Sci USA 92: 344-348.

23 Shen Z, Stryker GA, Mernaugh RL, Yu L, Yan H, et al. (2005) Singlechain fragment variable antibody piezoimmunosensors. Anal Chem 77: 797-805

24 Gunsalus RP, Yanofsky C (1980) Nucleotide sequence and expression of Escherichia coli trpR, the structural gene for the trp aporepressor. Proc Natl Acad Sci U S A 77: 7117-7121.

25 Kato M, Chiba T, Hanyu Y (2011) Inhibition of Gaussia luciferase Activity by a Monoclonal Antibody. Curr Enzym Inhib7: 229-235.

26 Kato M, Hanyu Y (2013) Construction of an scFv library by enzymatic assembly of VL and VH genes. J Immunol Methods 396: 15-22.

27 Esposito D, Chatterjee DK (2006) Enhancement of soluble protein expression through the use of fusion tags. Curr Opin Biotechnol 17: 353-358.

28 Khan MA, Islam MM, Kuroda Y (2013) Analysis of protein aggregation kinetics using short amino acid peptide tags. Biochim Biophys Acta 1834: 2107-2115

29 Papworth M, Kolasinska P, Minczuk M (2006) Designer zinc-finger proteins and their applications. Gene 366: 27-38.

30 Zeevi V, Tovkach A, Tzfira T (2010) Artificial zinc finger nucleases for DNA cloning. Methods Mol Biol 649: 209-225.

31 Stolzenburg S, Bilsland A, Keith WN, Rots MG (2010) Modulation of gene expression using zinc finger-based artificial transcription factors. Methods Mol Biol 649: 117-132.

32 Günes C, Staacke D, von Wilcken-Bergmann B, Müller-Hill B (1996) Co-operative binding of two Trp repressor dimers to alpha- or betacentred trp operators. Mol Microbiol 20: 375-384.

33 Komeiji Y, Uebayasi M (1999) Change in conformation by DNApeptide association: molecular dynamics of the Hin-recombinasehixL complex. Biophys J 77: 123-138.

34 Elrod-Erickson M, Pabo CO (1999) Binding studies with mutants of Zif268. Contribution of individual side chains to binding affinity and specificity in the Zif268 zinc finger-DNA complex. J Biol Chem 274: 19281-19285

35 Chen X, Zaro JL, Shen WC (2013) Fusion protein linkers: property, design and functionality. Adv Drug Deliv Rev 65: 1357-1369.

36 Kato M, Hanyu Y (2015) Screening technologies for recombinant antibody libraries. Med Res Arch 2: 12-18. 